\title{
Resenhas
}





\section{Polinizadores do Brasil}

Klaus Hartfelder

T UDO indica que, com o cumprimento da lei sancionada em 2012, saberemos a partir de junho de 2013 o quanto pagamos de imposto indireto na compra de produtos de consumo. Vale a pena notar também que tal lei é oriunda de uma iniciativa popular, não de uma iniciativa parlamentar. Bom, então, saberemos o quanto pagamos e o que (não) recebemos de volta em forma de serviços governamentais.

$\mathrm{O}$ que isso tem a ver com o livro Polinizadores do Brasil, de autoria dos doutores Vera Imperatriz Imperatriz-Fonseca, Dora Ann Lange Canhos, Denise de Araujo Alves e Antonio Mauro Saraiva, que organizaram, com a ajuda e contribuições de 85 especialistas, um livro de referência sobre a situação dos polinizadores no Brasil? Tem muita ver, pois o que os dados apresentados deixam à luz é que recebemos serviços de altíssimo valor, pelos quais não pagamos nada ou pouco, pelo menos por enquanto. São os chamados serviços ambientais ou ecossistêmicos (ecosystem services) que tomamos de graça. Como bem lembrado pelos organizadores, no primeiro capítulo, a contribuição dos polinizadores visa dois pilares centrais do bem-estar, o da conservação da biodiversidade dos ecossistemas terrestre e o da atividade agrícola direcionada à produção de alimentos e de "commodities". Citando Ollerton et al. (2011), 87,5\% das espécies de plantas com flores dependem de uma forma ou outra de polinizadores, e baseado em dados de Klein et al. (2007), de Gallai et al. (2009) e de Potts et al. (2011), os organizadores enfatizam que
$75 \%$ da alimentação humana provêm direta ou indiretamente de plantas polinizadas ou beneficiadas de insetos, aves e pequenos mamíferos. Em termos de valores monetários isso significa que, em média, o valor das culturas que dependem da polinização é de quase um trilhão de dólares, enquanto o das que não dependem de polinização não chega a nem um quarto desse valor. Somente para a abelha europeia, Apis mellifera, que é o polinizador mais bem estudado e mais manejado, calcula-se que, para o ano 2007, o valor de seus serviços ecossistêmicos, em forma de polinização, era de 212 bilhões de dólares, enquanto o valor global do produto principal das colmeias, o mel exportado chegou a apenas 1,25 bilhão de dólares, assim sendo, nem a $5 \%$ do valor dos serviços como polinizador.

Então, o que pagamos para tais serviços? Na América do Norte e em partes da Europa, os apicultores são pagos para colocar colmeias de Apis mellifera nos cultivos na época da florada; já no Brasil, não há tais acordos e, ademais, como no resto do mundo, continuamos a diminuir os hábitats disponíveis para os polinizadores. Voltando à questão inicial, da informação na conta dos impostos indiretos pagos na compra de produtos e serviços, somos péssimos pagadores, pelo menos por enquanto.

Como destacado na primeira parte do livro, a percepção mudou a partir dos anos 1970, quando um ectoparasita do gênero $A$ pis, a varroa, começou a causar grandes prejuízos aos apicultores do $\mathrm{He}$ misfério Norte, o que colocou em evi- 
dência a alta dependência da agricultura nesse polinizador e nos abriu os olhos para polinizadores alternativos. Também contribuiu para essa percepção a sucessiva automatização da produção de certos cultivos em sistemas estufa, levando ao aperfeiçoamento da produção racional de colônias de abelhas mamangavas, especialmente da espécie Bombus terrestris. Assim, introduziu-se na agenda da Conferência Rio 1992 das Nações Unidas a iniciativa de proteção dos polinizadores.

No Brasil, isso resultou na "Declaração de São Paulo sobre os polinizadores" (Dias et al., 1999) e culminou com a formação da "Iniciativa Brasileira de Polinizadores" (IBP), tendo como a sua principal liderança a Profa. Dra. Vera Lucia Imperatriz Fonseca, organizadora principal do atual volume. Junto às demais iniciativas internacionais e globais, o projeto tem como objetivo o uso sustentável e restauração da diversidade de polinizadores, especialmente de espécies nativas, na agricultura e nos ecossistemas do Brasil.

Além de inúmeros trabalhos em campo, gerando dados precisos sobre as características do processo de visita e polinização de plantas por animais, o projeto da IBP também se empenhou na digitalização dos dados das principais coleções zoológicas e da introdução desses dados em modelos matemáticos passíveis à predição de cenários futuros, considerando questões de sucessiva fragmentação de hábitats e alterações climáticas. Tais dados e modelos são apresentados de forma brilhante e exaustiva no atual compêndio, colocando o ponto no " $\mathrm{i}$ " nas questões de levantamentos de polinizadores e seu papel nos ecossistemas em geral e nos dominados por atividade agrícolas, e por fim, na formulação de políticas públicas.
Assim, são apresentados na segunda parte do livro dados gerais sobre questões globais e do Brasil referentes à estrutura de paisagens e informações científicas disponíveis, antes de referenciar os diferentes grupos de polinizadores nos ecossistemas brasileiros. A começar com os vertebrados, apresenta-se uma listagem extensa com informações sobre 338 espécies de polinizadores efetivos ou potenciais, sendo na sua maioria voadores, aves (234) e morcegos (48), seguido de 54 espécies de mamíferos não voadores e duas espécies de répteis. Para todas essas são listadas a sua ocorrência em certos biomas e informações sobre preferência de temperatura e altitude.

Em seguida são apresentados dados sobre mariposas esfingídeos e de besouros que contribuem para a polinização e até são polinizadores exclusivos e altamente especializados de determinadas plantas de interesse econômico, tais como graviola e palmeiras (babaçu, piaçava, dendezeiro, entre outros).

Já a terceira parte da obra tem o seu foco nas abelhas como polinizadores, a começar com um levantamento da literatura sobre abelhas solitárias, seguido de considerações sobre a abelha africanizada, Apis mellifera, no contexto Brasil. Incluem-se dados sobre a sanidade dessas, com foco sobre patógenos biológicos e agrotóxicos como sendo as principais causas da doença ou síndrome de colapso das colmeias (colony collapse disease) em aspectos mundiais e a respectiva situação no Brasil. Obviamente, não podia faltar nessa parte um capítulo sobre as abelhas sem ferrão, focada sobre a situação e perspectivas da meliponicultura na polinização agrícola. Nesse capítulo, os colaboradores do grupo da Profa. Vera Lucia Imperatriz-Fonseca 
compilaram dados importantes sobre as espécies, a sua distribuição geográfica e facilidade ou potencial de criação.

A quarta seção, constituída de oito capítulos, documenta problemas a serem solucionados e ferramentas já desenvolvidas ou em fase de desenvolvimento, direcionadas à conservação de polinizadores, especialmente abelhas solitárias e sociais. Um dos grandes problemas aguardando solução se refere a questões de taxonomia, sendo o principal o número restrito de especialista capazes de classificar espécimes da fauna silvestre ou oriundos de esforços de biomonitoramento em áreas de atividade agrícola. Estima-se que, no caso da megadiversidade de abelhas no Brasil, com 9\% de todas as espécies de abelhas do mundo, seriam necessários dois a três mil anos para os atuais 140 especialistas descreverem e classificarem todos os exemplares coletados. Essa tarefa gigantesca pode, em parte, tirar proveito de metodologias da biologia molecular, o DNA barcoding. Essa, porém, também necessita de supervisão ou direcionamento pelo respectivo taxonomista. Uma ferramenta importante nessa tarefa certamente é a digitalização das coleções de referência, para facilitar e dinamizar o acesso às informações destas.

Um segundo tipo de ferramentas para conservação de polinizadores são os modelos de previsão climática, tendo em vista as tendências do aquecimento global. Tais modelos foram usados em estudos do possível impacto das mudanças climáticas previstas sobre abelhas nativas, as solitárias do gênero Centris, e as sociais do gênero Melipona, como também na avaliação das consequências da já ocorrida introdução de polinizadores exóticos, como a mamangava Bombus terrestris.
Obviamente, tal modelagem de fatores abióticos tem consequências diretas também sobre as plantas visitadas e utilizadas pelos respectivos polinizadores. Sendo de principal importância para polinizadores especializados (mono- ou oligolécitos), informações palinológicos (obtidas de estudos do pólen coletado, especialmente por abelhas) serão de grande valia para o entendimento das relações planta-polinizador.

Por final, uma ferramenta importante, objetivando a conservação de polinizadores, é a disponibilização, divulgação e popularização de informações sobre polinizadores e as suas relações com plantas em agrossistemas. A Rede Temática de Polinizadores (PTN), associada à Rede Interamericana de Informações em Biodiversidade (IABIN) integra coleções e bases de dados importantes da maioria dos países da América Latina, incluindo oito instituições da rede speciesLink no Brasil. Várias ferramentas de digitalização dessa rede foram desenvolvidas na Escola Politécnica da USP, com apoio da Fapesp. Outra ferramenta importante dentro da speciesLink é o Catálogo de Abelhas Moure, organizado por pesquisadores da Universidade Federal do Paraná e publicado em 2007, que, mundialmente, se tornou uma das principais obras de referência para pesquisas sobre abelhas.

Por fim, a quinta seção do livro, dividida em dois capítulos, é dedicada à discussão de questões de políticas públicas e propostas de estratégias de ação. Nessa seção, os organizadores do livro, junto a funcionários do Ministério de Ciência e Tecnologia e das sociedades civis de interesse público Fundbio (Fundo Brasileiro de Biodiversidade) e Cria (Centro de Referência em Informação Ambien- 


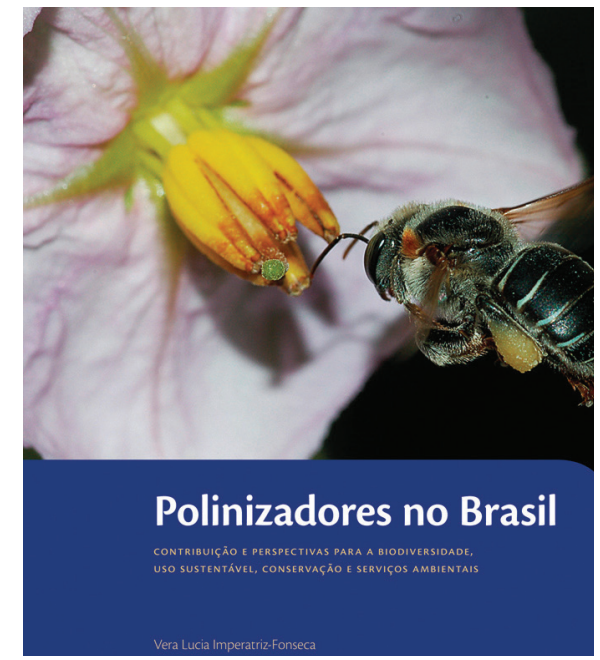

IMPERATRIZ-FONSECA, V. L. et al. Polinizadores do Brasil - Contribuição e perspectivas para a biodiversidade, uso sustentável, conservação e serviços ambientais.

São Paulo: Edusp, 2012. 488p.

tal), apresentam uma análise abrangente e crítica das políticas públicas. A seção se destaca pelo resumo da história da legislação e das ações referentes à questão de polinizadores e, especialmente, pela compilação em quatro tabelas das leis e decretos, contrapondo um por um os seus objetivos e falhas e propondo respectivas mudanças e complementações.

Em conclusão, o livro Polinizadores no Brasil, com os seus 23 capítulos divididos em cinco áreas temáticas, é uma obra de referência para todos os setores diretamente envolvidos e que necessitam informações sobre o estado da arte, como agricultores que cultivam plantas que necessitam de polinizadores para garantir boa produtividade, tanto em sistemas abertos quanto em estufas, para biólogos interessados na relação planta- polinizador, para economistas que estudam o mercado da produção agrícola, e para políticos e funcionários dos governos federal, estaduais e municipais. Ademais, a clareza da escrita e a organização de cada capítulo, com informações pontuais dentro do texto, com tabelas que referenciam o estado da arte com os respectivos desafios, e com muitos gráficos ilustrativos, tornam esse livro também uma fonte de informações valiosas para o leigo interessado.
Klaus Hartfelder é professor da Faculdade de Medicina de Ribeirão Preto, Universidade de São Paulo.

@-klaus@fmrp.usp.br 